\title{
KONVOLUSI DARI PEUBAH ACAK BINOMIAL NEGATIF
}

\author{
NUR ADE YANI \\ Program Studi Magister Matematika, \\ Fakultas Matematika dan Ilmu Pengetahuan Alam, Universitas Andalas, \\ Kampus UNAND Limau Manis Padang, Indonesia, \\ ade_yani@mail.com
}

\begin{abstract}
Abstrak. Dalam penelitian ini dikaji konvolusi dari peubah acak binomial negatif dengan menggunakan metode fungsi pembangkit momen. Kajian ini memberikan fungsi kepadatan peluang dan fungsi distribusi kumulatif dari jumlah peubah acak binomial negatif.
\end{abstract}

Kata Kunci: Distribusi binomial negatif, Deret berpangkat

\section{Pendahuluan}

Misalkan terdapat distribusi binomial negatif dengan peubah acak $Y_{j}, j=1,2, \ldots, n$ dan parameter $\left(\alpha_{j}, p_{j}\right)$. Fungsi kepadatan peluang dari $Y_{j}$ dapat dirumuskan sebagai berikut,

$$
P\left(Y_{j}=y\right)=\frac{\Gamma\left(\alpha_{j}+y\right)}{\Gamma\left(\alpha_{j}\right) y !} p_{j}^{\alpha_{j}}\left(1-p_{j}\right)^{y}
$$

untuk $0<p_{j}<1$ dan $0<\alpha_{j}<\infty$.

Misalkan $S=Y_{1}+Y_{2}+\cdots+Y_{n}$ adalah jumlah dari peubah acak binomial negatif, dengan masing-masing peubah acak $Y_{j}$ memiliki fungsi distribusi binomial negatif yang kemudian dapat ditentukan nilai harapan, variansi serta fungsi pembangkit momennya. Dalam teori peluang, distribusi dari jumlah peubah acak bebas dinamakan dengan konvolusi. Penggunaan metode konvolusi sering digunakan untuk jumlah dua peubah acak bebas. Untuk menentukan distribusi lebih dari dua peubah acak bebas digunakan proses konvolusi yang tidak mudah untuk ditentukan.

Metode lain yang dapat digunakan untuk menentukan distribusi dari jumlah peubah acak bebas adalah dengan metode fungsi pembangkit momen. Dengan metode fungsi pembangkit momen dapat ditentukan fungsi kepadatan peluang dan fungsi distribusi kumulatif dari jumlah peubah acak bebas binomial negatif. 


\section{Konvolusi dari Peubah acak Binomial Negatif dengan Parameter yang Berbeda}

Misalkan $Y_{j} \sim B N\left(\alpha_{j}, p_{j}\right)$ memiliki fungsi kepadatan peluang, maka fungsi pembangkit momen dari $Y_{j}$ adalah

$$
M_{Y_{j}}(t)=\left(\frac{1-q_{j} e^{t}}{p_{j}}\right)^{-\alpha_{j}} .
$$

Dengan memisalkan $r_{j}=q_{j} / p_{j}$ dan $\tilde{t}=e^{t}-1$, maka fungsi pembangkit momen dari $Y_{j}$ dapat ditulis kembali dalam bentuk

$$
M_{Y_{j}}(t)=\left(1-r_{j} \widetilde{t}\right)^{-\alpha_{j}},
$$

dan fungsi pembangkit momen $S$ dapat diperoleh

$$
M_{S}(t)=\prod_{j=1}^{n}\left(1-r_{j} \widetilde{t}\right)^{-\alpha_{j}} .
$$

Selanjutnya akan ditentukan fungsi kepadatan peluang $S$, yang akan dijelaskan pada teorema berikut ini.

Teorema 2.1. Misalkan $Y_{j}, j=1,2, \ldots, n$ adalah peubah acak binomial negatif dengan parameter $\left(\alpha+k, p_{1}\right), S=\sum_{j=1}^{n} Y_{j}, p_{1}=\max _{j}\left(p_{j}\right)$, dan $\alpha=\alpha_{1}+\alpha_{2}+$ $\alpha_{3}+\cdots+\alpha_{n}$, maka fungsi kepadatan peluang dari $S$ adalah

$$
P(S=s)=R \sum_{k=0}^{\infty} \delta_{k} \frac{\Gamma(\alpha+s+k)}{\Gamma(\alpha+k) s !} p_{1}^{\alpha+k}\left(1-p_{1}\right)^{s},
$$

untuk $s=0,1,2, \cdots$ dan 0 untuk yang lainnya.

Bukti. Notasikan

$$
R=\prod_{j=1}^{n}\left(\frac{q_{j} p_{1}}{q_{1} p_{j}}\right)^{-\alpha_{j}}
$$

untuk

$$
\begin{gathered}
\delta_{0}=1, \\
\delta_{k+1}=\frac{1}{k+1} \sum_{i=1}^{k+1} i \xi_{i} \delta_{k+1-i}, \quad k=0,1, \cdots, \\
\xi_{i}=\sum_{j=1}^{n} \frac{\alpha_{j}\left(1-q_{1} p_{j} / q_{j} p_{1}\right)^{i}}{i} .
\end{gathered}
$$

Dengan mengasumsikan $r_{1}=\min _{j}\left(r_{j}\right)$ dan menotasikan

$$
1-r_{j} \widetilde{t}=\left(1-r_{1} \widetilde{t}\right)\left(\frac{r_{j}}{r_{1}}\right)\left(1-\left(1-\frac{r_{1}}{r_{j}}\right) /\left(1-r_{1} \widetilde{t}\right)\right.
$$


24 Nur Ade Yani

maka diperoleh

$$
M_{S}(t)=\prod_{j=1}^{n}\left(\left(1-r_{1} \widetilde{t}\right)\left(\frac{r_{j}}{r_{1}}\right)\left(1-\left(1-\frac{r_{1}}{r_{j}}\right) /\left(1-r_{1} \widetilde{t}\right)\right)^{-\alpha_{j}} .\right.
$$

Dengan fungsi pembangkit kumulan maka dapat ditulis

$$
\log M_{S}(t)=\log \left[\left(1-r_{1} \widetilde{t}\right)^{-\alpha} R\right]+\sum_{k=1}^{\infty} \xi_{k}\left(1-r_{1} \widetilde{t}\right)^{-k} .
$$

selanjutnya dengan memperhatikan kembali $M_{S}(t)$,

$$
\begin{aligned}
M_{S}(t) & =\left(1-r_{1} \widetilde{t}\right)^{-\alpha} R \cdot \exp \left(\sum_{k=1}^{\infty} \xi_{k}\left(1-r_{1} \widetilde{t}\right)^{-k}\right) \\
& =R \sum_{k=0}^{\infty} \delta_{k}\left(1-r_{1} \widetilde{t}\right)^{-(\alpha+k)} .
\end{aligned}
$$

Dengan menjabarkan kembali fungsi pembangkit momen $S$, diperoleh

$$
M_{s}(t)=\sum_{s=0}^{\infty} e^{t s} R \sum_{k=0}^{\infty} \delta_{k}\left(\begin{array}{c}
\alpha+k+s-1 \\
s
\end{array}\right) p_{1}^{(\alpha+k)}\left(1-p_{1}\right)^{s} .
$$

Maka sesuai dengan definisi fungsi pembangkit momen, persamaan (3.10) memuat fungsi kepadatan peluang dari $S$ yang dapat ditulis sebagai

$$
P(S=s)=R \sum_{k=0}^{\infty} \delta_{k} \frac{\Gamma(\alpha+k+s)}{\Gamma(\alpha+k) s !} p_{1}^{(\alpha+k)}\left(1-p_{1}\right)^{s} .
$$

Selanjutnya akan ditentukan fungsi distribusi kumulatif dari $S$ yang akan ditentukan dari fungsi kepadatan peluang yang diperoleh pada bahagian sebelumnya. Sehingga untuk menentukannya diberikan dalam suatu akibat dari Teorema 2.1.

Akibat 2.2. Misalkan $Y_{j}, j=1,2, \cdots, n$ adalah peubah acak binomial negatif dengan parameter $\left(\alpha+k, p_{1}\right), S=\sum_{j=1}^{n} Y_{j}, \alpha=\alpha_{1}+\alpha_{2}+\cdots+\alpha_{n}, p_{1}=\max _{j}\left(p_{j}\right)$ dan $R=\prod_{j=1}^{n}\left(\frac{q_{j} p_{1}}{q_{1} p_{j}}\right)^{-\alpha_{j}}$, maka fungsi distribusi kumulatif dari $S$ adalah

$$
F_{S}(s)=R \sum_{k=0}^{\infty} \delta_{k} \sum_{\tilde{s}=0}^{s} \frac{\Gamma(\alpha+\tilde{s}+k)}{\Gamma(\alpha+k) \tilde{s} !} p_{1}^{\alpha+k}\left(1-p_{1}\right)^{\tilde{s}}
$$

untuk $\tilde{s}=0,1,2, \cdots$.

Bukti. Jika $F_{S}(s)$ adalah fungsi distribusi kumulatif dari distribusi $S$ apabila deret yang dibentuk konvergen seragam, selanjutnya akan dibuktikan deret tersebut konvergen seragam dengan menggunakan teorema M-Weierstrass. Perhatikan kembali fungsi distribusi kumulatif peubah acak $S$

$$
F_{S}(s)=R \sum_{k=0}^{\infty} \delta_{k} \sum_{\tilde{s}=0}^{s} \frac{\Gamma(\alpha+\tilde{s}+k)}{\Gamma(\alpha+k) \tilde{s} !} p_{1}^{\alpha+k}\left(1-p_{1}\right)^{\tilde{s}} .
$$


Notasikan $\left(1-q_{1} p_{j} / q_{j} p_{1}\right)>0$ untuk $j=2,3, \cdots, n$ dan untuk $i=1,2, \cdots, \eta=$ $\max _{2 \leq j \leq n}\left(1-q_{1} p_{j} / q_{j} p_{1}\right)$, dan dari persamaan $(2.4)$

$$
\begin{aligned}
\left|\xi_{i}\right| & =\left|\sum_{j=1}^{n} \frac{\alpha_{j}\left(1-q_{1} p_{j} / q_{j} p_{1}\right)^{i}}{i}\right| \\
\left|\xi_{i}\right| \leq \alpha \frac{\eta^{i}}{i !} . & \\
\left|\delta_{k+1}\right| & =\left|\frac{1}{k+1} \sum_{i=1}^{k+1} i \xi_{i} \delta_{k+1-i}\right| \\
& \leq \frac{\alpha}{k+1} \sum_{i=1}^{k+1} \eta^{i}\left|\delta_{k+1-i}\right| .
\end{aligned}
$$

Selanjutnya dengan menggunakan induksi akan terlihat

$$
\begin{aligned}
\left|\delta_{k+1}\right| & \leq \frac{\alpha}{k+1}\left(\eta^{1}\left|\delta_{k}\right|+\eta^{2}\left|\delta_{k-1}\right|+\cdots+\eta^{k+1}\left|\delta_{0}\right|\right) \\
& \leq \frac{\eta^{k+1} \alpha_{(k+1)}}{(k+1) !}
\end{aligned}
$$

Sehingga

$$
p r_{s} \leq \frac{\Gamma(\tilde{s}+\alpha) R p_{1}^{\alpha}\left(1-p_{1}\right)^{\tilde{s}}}{\Gamma(\alpha) \tilde{s} !(1-\eta)^{\tilde{s}+\alpha}}
$$

ini berarti bahwa deret dari fungsi distribusi kumulatif memenuhi kekonvergenan seragam.

Dari Akibat 2.2 dapat disimpulkan bahwa

$$
\sum_{k=0}^{\infty} R \delta_{k}=1
$$

dengan kata lain $R \delta_{k}$ adalah suatu fungsi kepadatan peluang dari suatu peubah acak, sehingga $S$ merupakan peubah acak dari distribusi tertentu melalui proses pencampuran peubah-peubah acak, yang dapat dijelaskan pada teorema berikut ini.

Teorema 2.3. Peubah acak $S$ adalah peubah acak dari distribusi negatif binomial campuran dengan parameter $(\alpha+K), K$ adalah peubah acak dengan fungsi kepadatan peluang

$$
P(K=k)=R \delta_{k}, \quad k=0,1, \cdots
$$

dimana

$$
R=\prod_{j=1}^{n}\left(\frac{q_{j} p_{1}}{q_{1} p_{j}}\right)^{-\alpha_{j}}
$$


dan

$$
\delta_{k+1}=\frac{1}{k+1} \sum_{i=1}^{k+1} i \xi_{i} \delta_{k+1-i}, \quad k=0,1, \cdots \text { untuk } \delta_{0}=1
$$

\section{Konvolusi dari Peubah Acak Binomial Negatif dengan Parameter yang Sama}

Selanjutnya akan dikaji konvolusi dari peubah acak negatif binomial dengan parameter yang sama, dalam hal ini nilai parameter $(\alpha, p)$ dari setiap kejadian sama. Fungsi pembangkit momen dari peubah acak $Y_{j} \sim B N(\alpha, p)$ adalah

$$
M_{Y_{j}}(t)=\left(\frac{1-q e^{t}}{p}\right)^{-\alpha}
$$

Teorema 3.1. Misalkan $Y_{j}$ adalah peubah acak binomial negatif dengan parameter $(\Lambda, p), S=\sum_{j=1}^{n} Y_{j}, \Lambda=n \alpha$ maka fungsi kepadatan peluang dari $S$ adalah

$$
P(S=s)=\frac{\Gamma(s+\Lambda)}{\Gamma(\Lambda) s !}(1-p)^{s} p^{\Lambda}
$$

untuk $s=0,1,2, \cdots$ dan 0 untuk yang lainnya.

Bukti. Misalkan $r=q / p, \tilde{t}=e^{t}-1$ dan $\Lambda=n \alpha$, maka fungsi pembangkit momen dari $Y_{j}$ dapat ditulis kembali dalam bentuk

$$
\begin{aligned}
M_{Y_{j}}(t) & =\left(\frac{1-q e^{t}}{p}\right)^{-\alpha} \\
& =(1-r \tilde{t})^{-\alpha} .
\end{aligned}
$$

Untuk menentukan fungsi pembangkit momen $S$ digunakan teorema dari fungsi pembangkit momen dari jumlah peubah acak bebas, sehingga fungsi pembangkit momen $S$ dapat ditulis

$$
M_{S}(t)=(1-r \tilde{t})^{-\Lambda}
$$

Selanjutnya akan ditentukan fungsi kepadatan peluang dari $S$ dengan parameter yang sama.

$$
\begin{aligned}
M_{S}(t) & =(1-r \tilde{t})^{-\Lambda} \\
& =p^{\Lambda}\left(1-q e^{t}\right)^{-\Lambda} .
\end{aligned}
$$

Berdasarkan teorema Binomial, persamaan di atas dapat ditulis kembali menjadi

$$
\begin{aligned}
M_{S}(t) & =p^{\Lambda}\left(1-q e^{t}\right)^{-\Lambda} \\
& =\sum_{s=0}^{\infty} e^{t s} \frac{(s+\Lambda-1) !}{(\Lambda-1) ! s !}(1-P)^{s} p^{\Lambda} .
\end{aligned}
$$

Sehingga fungsi pembangkit momen $S$ memuat fungsi kepadatan peluang dari $S . \square$ 


\section{Kesimpulan}

Misalkan $Y_{j}, j=1,2, \cdots$ adalah peubah acak yang berdistribusi negatif binomial $Y_{j} \sim B N\left(\alpha_{j}, p_{j}\right)$, maka fungsi kepadatan peluang $Y_{j}$ adalah

$$
P\left(Y_{j}=y\right)=\frac{\Gamma\left(\alpha_{j}+y\right)}{\Gamma\left(\alpha_{j}\right) y !} p_{j}^{\alpha_{j}}\left(1-p_{j}\right)^{y} .
$$

Jika $S=Y_{1}+Y_{2}+\cdots+Y_{n}$ adalah jumlah dari peubah acak bebas berdistribusi negatif binomial atau disebut juga dengan konvolusi, maka

$$
M_{S}(t)=\prod_{j=1}^{n}\left(1-r_{j} \widetilde{t}\right)^{-\alpha_{j}}
$$

dengan fungsi kepadatan peluang

$$
P(S=s)=R \sum_{k=0}^{\infty} \delta_{k} \frac{\Gamma(\alpha+s+k)}{\Gamma(\alpha+k) s !} p_{1}^{\alpha+k}\left(1-p_{1}\right)^{s} .
$$

Dan dari fungsi distribusi yang diperoleh maka distribusi dari $S \sim B N\left(\alpha+K, p_{1}\right)$ adalah jumlah dari peubah acak bebas ninomial negatif dengan jumlah parameter $\alpha+K$ dengan $K$ peubah acak bebas, fungsi kepadatan peluangnya adalah

$$
P(K=k)=R \delta_{k}, \quad k=0,1, \cdots .
$$

Apabila peubah acak binomial negatif dikonvolusikan dimana parameter setiap peubah acak sama yaitu $(\alpha, p)$ maka fungsi kepadatan peluang adalah

$$
P(S=s)=\frac{\Gamma(s+\Lambda)}{\Gamma(\Lambda) s !}(1-p)^{s} p^{\Lambda} .
$$

\section{Ucapan Terima kasih}

Penulis mengucapkan terima kasih kepada Bapak Dr. Dodi Devianto, Ibu Dr.Maiyastri, Bapak Dr.Muhafzan, Bapak Dr. Admi Nazra, Ibu Dr. Lyra Yulianti, Bapak Dr. Mahdhivan Syafwan dan Ibu Ferra Yanuar yang telah memberikan masukan dan saran sehingga paper ini dapat diselesaikan dengan baik.

\section{Daftar Pustaka}

[1] Bain, L.J. dan M. Engelhardt. 1992. Introduction to Probability and Mathematical Statistics Second Edition. Duxbury Press, California.

[2] Barnet, S dan R, G, Cameron. 1985. Introduction to Mathematical Control Theory Second Edition. Clarendon Preess. Oxford.

[3] Brown,J.W. dan Churchill, R.V. 1996.Complex Variables and Applications.Ed. Ke- 6, Mc. Grawhill, Singapore.

[4] Furman, E. 2006. On the convolution of the negative binomial random variables. Statistic and probability letters, Elsevier Academic Press, California.

[5] Gnedenko, B. V. dan A. N. Kolmogorov. 1968. Limit Distributions for Sums of Independent Random Variables. $2^{\text {nd }}$ ed, Addison-Wesley, London.

[6] Rosen, H. K. 2003. Discrete Mathematics and its Applications. $5^{\text {th }}$ ed. McGrawHill, New York. 